Jasmine Lee, OMS III*, Chun Maung, OMS III, Jenzel Espares, OMS III, Justin Chen, OMS III, Frenda Yip, OMS III, Willis Lin, OMS II, Lauren Zhao, MS, OMS II and To Shan Li, DO

\title{
Knowledge of osteopathic manipulative medicine and osteopathic physicians in a New York South Asian community
}

https://doi.org/10.1515/jom-2021-0060

Received February 18, 2021; accepted May 27, 2021;

published online July 19, 2021

\section{Abstract}

Context: Research regarding patient awareness of osteopathic manipulative medicine (OMM) can help identify barriers and factors limiting patient knowledge. Levels of knowledge about OMM and osteopathic physicians have been studied in New York's Chinese and Korean populations, but have not previously been investigated in the South Asian population.

Objectives: To assess the knowledge of OMM and osteopathic physicians within a South Asian community of New York.

Methods: A cross-sectional study was designed in which a culturally appropriate survey, provided in both English and Hindi, was administered to study participants in order to measure knowledge of osteopathic medicine. The study utilized convenience sampling and distributed surveys to individuals who identified themselves of South Asian descent at high traffic sites in Hicksville, New York. The survey contained 10 questions, assessing the individual's knowledge of osteopathic medicine. The Kruskal-Wallis and Chi-Square tests were employed to determine statistical significance of the data obtained from the surveys.

Results: The survey was conducted on 100 participants in Hicksville, New York. The respondent demographics

*Corresponding author: Jasmine Lee, OMS III, New York Institute of Technology College of Osteopathic Medicine, PO Box 8000, Rm 134 Serota Building, Northern Blvd, Old Westbury, NY 11568, USA

E-mail: jlee90@nyit.edu

Chun Maung, OMS III, Jenzel Espares, OMS III, Justin Chen, OMS III, Frenda Yip, OMS III, Willis Lin, OMS II and Lauren Zhao, MS, OMS II, New York Institute of Technology College of Osteopathic Medicine, Old Westbury, NY, USA

To Shan Li, DO, Department of Osteopathic Manipulative Medicine, New York Institute of Technology College of Osteopathic Medicine, Old Westbury, NY, USA

Ә Open Access. (C) 2021 Jasmine Lee et al., published by De Gruyter. ((c)) BY International License. included 53 males and 47 females with an average age of $41.2 \pm 16.3$ years old. There were 34 (34\%) participants who had heard of osteopathic manipulative medicine (OMM) and $26(26 \%)$ participants who had knowledge of doctor of osteopathic medicine (DO) physicians. Respondents were found more likely to have knowledge of DOs if they were born in the United States (US) vs. other countries (US, 8 of 14 [57.1\%] vs. others, 18 of 86 [20.9\%]; $\mathrm{p}=0.006$ ) or lived longer in the US (11 of 26 [42.3\%], p=0.039). Participants who spoke a nonEnglish primary language were also found less likely to have knowledge of DOs as they made up 46 of the 58 respondents who indicated no knowledge $(79.3 \%, \mathrm{p}=0.042)$.

Conclusions: A general lack of knowledge of DOs and OMM exists within the South Asian community of Hicksville, New York and lower levels of awareness were found among participants who were male, born outside the US, had a language other than English as their primary language, and had spent less time in the US. Additional educational resources may be implemented to increase awareness of DOs and OMM among this and similar communities.

Keywords: DO; knowledge; omm; osteopathic medicine; south Asian.

Osteopathic medicine, developed in the late 19th century by A.T. Still [1], emphasizes the interrelated unity of all systems in the body, each working with the other to heal in times of illness [2]. The osteopathic approach to care can include osteopathic manipulative medicine (OMM), a therapeutic form of treatment that uses manual pressure or force [2, 3]. In the US, osteopathic physicians, also called doctors of osteopathic medicine (DOs), receive a comprehensive medical education where osteopathic principles and OMM are integrated across the medical curriculum [4]. Outside the US, osteopaths are licensed to practice solely osteopathic manipulation. Although DOs have full physician practice rights in over 50 countries, there is still a lack of understanding of osteopathic medicine and its treatment methods on patients who come to the US from other countries [5-7]. Osteopathy is a branch of medical practice that can also be 
practiced internationally and focuses primarily on treating disorders pertaining to the musculoskeletal (MSK) system. The purpose of this survey study was to assess the knowledge of OMM and osteopathic physicians among the South Asian population of Hicksville, New York.

We hypothesized that there would be a lack of osteopathic knowledge in this particular community, and we designed this project as a basis for expanding research regarding patients' awareness of and patients' barriers or limits to understanding osteopathic medicine. Furthermore, this research could help disaggregate data on Asian populations. Existing national health data about the knowledge of osteopathic medicine in the United States is especially vague about minorities and reports them under one group. For example, data from OSTEOSURV 1998, 2000, and 2010, which assessed osteopathic recognition in the United States, categorized minorities into nonspecific groups including "Other (including $>1$ race)," "Nonwhite," and "Non-Hispanic." [8-10] This leads to an oversimplification of data on minorities and masks the lack of osteopathic knowledge in specific communities that may benefit considerably from education about OMM and osteopathic physicians. We hope that our study can provide more specific data on subgroups of Asian populations to help guide future efforts for education and outreach in these communities.

\section{Methods}

The study was deemed exempt by the NYIT Institutional Review Board for the Protection of Human Participants (Protocol BHS-1514).

\section{Participants and data collection}

Study participants were located within Hicksville, NY, USA a town in the Long Island region with a prolific South Asian community [11]. The most predominant Asian race reported in the 2019 United States Census for the city of Hicksville were Asian Indians (7,944 out of $12,722,62.4 \%)$ [11].

The research team used convenience sampling at high traffic sites in the Hicksville area, concentrated around grocery stores and restaurants (Figure 1). All subjects were approached verbally for potential inclusion into the study, and no other recruitment methods were used. All participants took the survey of their own volition; no compensation or any other form of incentive was offered. Collection took place from 1 to 6 pm on Friday, January 17, 2020.

Per the protocol approved by the NYIT Institutional Review Board, participants self-identified as South Asian and no further distinctions were made (i.e., mixed descent). No participants were excluded due to a language barrier between the research team and the medical student researchers. No other specific exclusion criteria was set, apart from any participant's lack of ability to give consent for participation in the study.

Participants were initially provided with a paper consent form (Supplementary Material), approved by the New York Institute of Technology (NYIT) Institutional Review Board, to review;

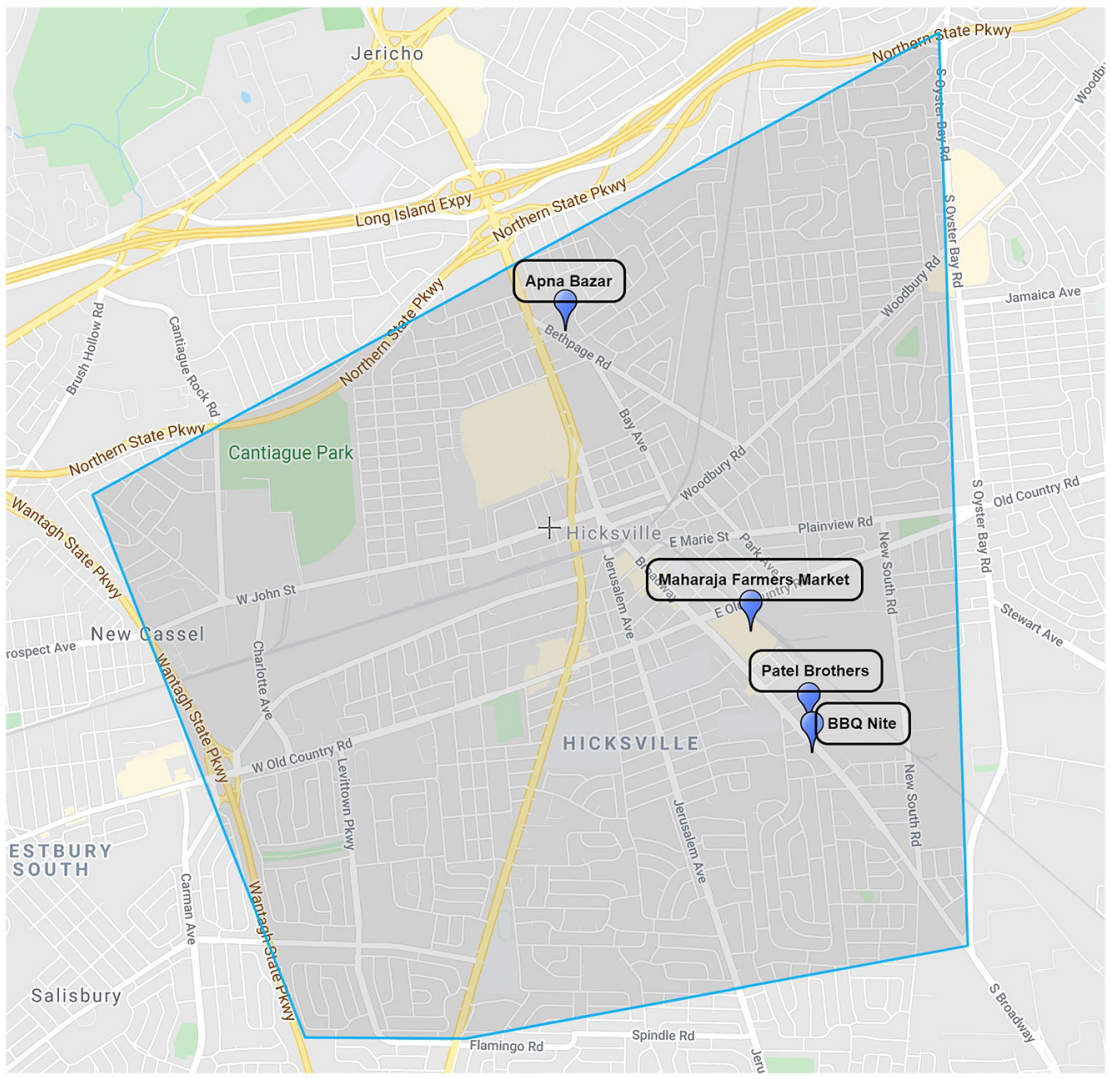

Figure 1: Data collection was conducted within Hicksville, NY at the marked locations. 
Table 1: Demographic characteristics of all participants.

\begin{tabular}{|c|c|c|c|c|c|c|c|c|c|}
\hline Characteristic & $\begin{array}{r}\text { All partici- } \\
\text { pants } \\
(n=100)\end{array}$ & $\begin{array}{l}\text { Knowledge of } \\
\text { OMM }(n=34)\end{array}$ & $\begin{array}{r}\text { No knowl- } \\
\text { edge of OMM } \\
(n=53)\end{array}$ & $\begin{array}{l}\text { Unsure } \\
(n=13)\end{array}$ & $\begin{array}{r}\text { p- } \\
\text { Value }\end{array}$ & $\begin{array}{r}\text { Knowledge of } \\
\text { what osteopathic } \\
\text { physicians do } \\
(n=26)\end{array}$ & $\begin{array}{r}\text { No knowledge of } \\
\text { what osteopathic } \\
\text { physicians do } \\
(n=58)\end{array}$ & $\begin{array}{l}\text { Unsure } \\
(n=16)\end{array}$ & $\begin{array}{r}\text { p- } \\
\text { Value }\end{array}$ \\
\hline \multicolumn{10}{|l|}{ Sex } \\
\hline Male & $53(53.0 \%)$ & $17(50.0 \%)$ & $33(62.3 \%)$ & $\begin{array}{r}3 \\
(23.1 \%)\end{array}$ & $0.036^{\star}$ & $12(46.2 \%)$ & $35(60.3 \%)$ & $\begin{array}{r}6 \\
(37.5 \%)\end{array}$ & 0.19 \\
\hline Female & 47 (47.0\%) & $17(50.0 \%)$ & $20(37.7 \%)$ & $\begin{array}{r}10 \\
(76.9 \%)\end{array}$ & & $14(53.8 \%)$ & $23(39.7 \%)$ & $\begin{array}{r}10 \\
(62.5 \%)\end{array}$ & \\
\hline \multicolumn{10}{|l|}{ Age, years } \\
\hline Median & 37 & 36.5 & 28 & 31 & & 31.5 & 38.5 & 36.5 & \\
\hline $18-29$ & 29 (29.0\%) & $13(38.2 \%)$ & $10(18.9 \%)$ & $\begin{array}{r}6 \\
(46.2 \%)\end{array}$ & 0.33 & $13(50.0 \%)$ & $13(22.4 \%)$ & $\begin{array}{r}3 \\
(18.8 \%)\end{array}$ & 0.80 \\
\hline $30-39$ & 27 (27.0\%) & $5(14.7 \%)$ & $19(35.8 \%)$ & $\begin{array}{r}3 \\
(23.1 \%)\end{array}$ & & $1(3.8 \%)$ & $18(31.0 \%)$ & $\begin{array}{r}8 \\
(50.0 \%)\end{array}$ & \\
\hline $40-49$ & $13(13.0 \%)$ & $1(2.9 \%)$ & $12(22.6 \%)$ & $0(0.0 \%)$ & & $1(3.8 \%)$ & 12 (20.7\%) & $0(0.0 \%)$ & \\
\hline $50-59$ & $16(16.0 \%)$ & $7(20.6 \%)$ & $6(11.3 \%)$ & $\begin{array}{r}3 \\
(23.1 \%)\end{array}$ & & $5(19.2 \%)$ & 7 (12.1\%) & $\begin{array}{r}4 \\
(25.0 \%)\end{array}$ & \\
\hline $60-69$ & $7(7.0 \%)$ & $4(11.8 \%)$ & $3(5.7 \%)$ & $0(0.0 \%)$ & & $3(11.5 \%)$ & $4(6.9 \%)$ & $0(0.0 \%)$ & \\
\hline $70-79$ & $5(5.0 \%)$ & $3(8.8 \%)$ & $1(1.9 \%)$ & $1(7.7 \%)$ & & $2(7.7 \%)$ & $2(3.4 \%)$ & $1(6.3 \%)$ & \\
\hline$\geq 80$ & $3(3.0 \%)$ & $1(2.9 \%)$ & $2(3.8 \%)$ & $0(0.0 \%)$ & & $1(3.8 \%)$ & $1(1.7 \%)$ & $0(0.0 \%)$ & \\
\hline \multicolumn{10}{|l|}{ Location of birth } \\
\hline United States & $14(14.0 \%)$ & $8(23.5 \%)$ & $4(7.5 \%)$ & $\begin{array}{r}2 \\
(15.4 \%)\end{array}$ & 0.11 & $8(30.8 \%)$ & $3(5.2 \%)$ & $\begin{array}{r}3 \\
(18.8 \%)\end{array}$ & $0.006^{*}$ \\
\hline Not US & $86(86.0 \%)$ & $26(76.0 \%)$ & 49 (92.5\%) & $\begin{array}{r}11 \\
(84.6 \%)\end{array}$ & & $18(69.2 \%)$ & 55 (94.8\%) & $\begin{array}{r}13 \\
(81.3 \%)\end{array}$ & \\
\hline Bangladesh & 5 (5.0\%) & $2(5.9 \%)$ & $3(5.7 \%)$ & $0(0.0 \%)$ & & $0(0.0 \%)$ & 4 (6.9\%) & $1(6.3 \%)$ & \\
\hline India & $52(52.0 \%)$ & $14(41.2 \%)$ & $28(52.8 \%)$ & $\begin{array}{r}10 \\
(76.9 \%)\end{array}$ & & $9(34.6 \%)$ & $34(58.6 \%)$ & $\begin{array}{r}9 \\
(56.3 \%)\end{array}$ & \\
\hline Pakistan & $21(21.0 \%)$ & $7(20.6 \%)$ & $13(24.5 \%)$ & $1(7.7 \%)$ & & $7(26.9 \%)$ & $12(20.7 \%)$ & $\begin{array}{r}2 \\
(12.5 \%)\end{array}$ & \\
\hline Other & $8(8.0 \%)$ & $3(8.8 \%)$ & $5(9.4 \%)$ & $0(0.0 \%)$ & & $2(7.7 \%)$ & $5(8.6 \%)$ & $1(6.3 \%)$ & \\
\hline \multicolumn{10}{|c|}{ Length of time in United States, years } \\
\hline $0-5$ & $19(19.0 \%)$ & $4(11.8 \%)$ & $11(20.8 \%)$ & $\begin{array}{r}4 \\
(30.8 \%)\end{array}$ & 0.08 & $2(7.7 \%)$ & $16(27.6 \%)$ & $1(6.3 \%)$ & $0.039 *$ \\
\hline $6-10$ & $12(12.0 \%)$ & $3(8.8 \%)$ & $9(17.0 \%)$ & $0(0.0 \%)$ & & $2(7.7 \%)$ & $9(15.5 \%)$ & $1(6.3 \%)$ & \\
\hline $11-15$ & $6(6.0 \%)$ & $0(0.0 \%)$ & 5 (9.4\%) & $1(7.7 \%)$ & & $0(0.0 \%)$ & $5(8.6 \%)$ & $1(6.3 \%)$ & \\
\hline $16-20$ & $17(17.0 \%)$ & $5(14.7 \%)$ & $10(18.9 \%)$ & $\begin{array}{r}2 \\
(15.4 \%)\end{array}$ & & $4(15.4 \%)$ & $8(13.8 \%)$ & $\begin{array}{r}5 \\
(31.3 \%)\end{array}$ & \\
\hline $21-25$ & $14(14.0 \%)$ & $7(20.6 \%)$ & $3(5.7 \%)$ & $\begin{array}{r}4 \\
(30.8 \%)\end{array}$ & & $7(26.9 \%)$ & $3(5.2 \%)$ & $\begin{array}{r}4 \\
(25.0 \%)\end{array}$ & \\
\hline$\geq 26$ & $32(32.0 \%)$ & $15(44.1 \%)$ & $15(28.3 \%)$ & $\begin{array}{r}2 \\
(15.4 \%)\end{array}$ & & $11(42.3 \%)$ & 27 (46.6\%) & $\begin{array}{r}4 \\
(25.0 \%)\end{array}$ & \\
\hline \multicolumn{10}{|c|}{ Highest level of education attained } \\
\hline High School & $13(13.0 \%)$ & $1(2.9 \%)$ & $9(17.0 \%)$ & $\begin{array}{r}3 \\
(23.1 \%)\end{array}$ & 0.28 & $1(3.8 \%)$ & $9(15.5 \%)$ & $\begin{array}{r}3 \\
(18.8 \%)\end{array}$ & 0.50 \\
\hline Associate & $1(1.0 \%)$ & $0(0.0 \%)$ & $0(0.0 \%)$ & $1(7.7 \%)$ & & $1(3.8 \%)$ & $0(0.0 \%)$ & $0(0.0 \%)$ & \\
\hline College & $48(48.0 \%)$ & $18(52.9 \%)$ & $25(47.2 \%)$ & $\begin{array}{r}5 \\
(38.5 \%)\end{array}$ & & $13(50.0 \%)$ & $29(50.0 \%)$ & $\begin{array}{r}6 \\
(37.5 \%)\end{array}$ & \\
\hline Graduate & $38(38.0 \%)$ & 15 (44.1\%) & $19(35.8 \%)$ & $\begin{array}{r}4 \\
(30.8 \%)\end{array}$ & & $11(42.3 \%)$ & $20(34.5 \%)$ & $\begin{array}{r}7 \\
(43.8 \%)\end{array}$ & \\
\hline \multicolumn{10}{|c|}{ English proficiency } \\
\hline Basic & $6(6.0 \%)$ & $0(0.0 \%)$ & 5 (9.4\%) & $1(7.7 \%)$ & 0.21 & $0(0.0 \%)$ & $6(10.3 \%)$ & $0(0.0 \%)$ & 0.13 \\
\hline Conversational & 25 (25.0\%) & $6(17.6 \%)$ & $16(30.2 \%)$ & $\begin{array}{r}3 \\
(23.1 \%)\end{array}$ & & $4(15.4 \%)$ & $16(27.6 \%)$ & $\begin{array}{r}5 \\
(31.3 \%)\end{array}$ & \\
\hline Fluent & $69(69.0 \%)$ & $28(82.4 \%)$ & 32 (60.4\%) & $\begin{array}{r}9 \\
(69.2 \%)\end{array}$ & & 22 (84.6\%) & $36(62.1 \%)$ & $\begin{array}{r}11 \\
(68.8 \%)\end{array}$ & \\
\hline
\end{tabular}


Table 1: (continued)

\begin{tabular}{|c|c|c|c|c|c|c|c|c|c|}
\hline Characteristic & $\begin{array}{r}\text { All partici- } \\
\text { pants } \\
(n=100)\end{array}$ & $\begin{array}{l}\text { Knowledge of } \\
\text { OMM }(n=34)\end{array}$ & $\begin{array}{r}\text { No knowl- } \\
\text { edge of OMM } \\
(n=53)\end{array}$ & $\begin{array}{l}\text { Unsure } \\
(n=13)\end{array}$ & $\begin{array}{r}\text { p- } \\
\text { Value }\end{array}$ & $\begin{array}{r}\text { Knowledge of } \\
\text { what osteopathic } \\
\text { physicians do } \\
(n=26)\end{array}$ & $\begin{array}{r}\text { No knowledge of } \\
\text { what osteopathic } \\
\text { physicians do } \\
(n=58)\end{array}$ & $\begin{array}{l}\text { Unsure } \\
(n=16)\end{array}$ & $\begin{array}{c}\text { p- } \\
\text { Value }\end{array}$ \\
\hline \multicolumn{10}{|c|}{ Primary language } \\
\hline English & $30(30.0 \%)$ & 12 (35.3\%) & $13(24.5 \%)$ & $\begin{array}{r}4 \\
(30.8 \%)\end{array}$ & 0.40 & $10(38.5 \%)$ & $12(20.7 \%)$ & $\begin{array}{r}8 \\
(50.0 \%)\end{array}$ & $0.042^{*}$ \\
\hline Not English & $70(70.0 \%)$ & 22 (64.7\%) & $40(75.5 \%)$ & $\begin{array}{r}9 \\
(69.2 \%)\end{array}$ & & $16(61.5 \%)$ & $46(79.3 \%)$ & $\begin{array}{r}8 \\
(50.0 \%)\end{array}$ & \\
\hline Bengali & $3(3.0 \%)$ & $1(2.9 \%)$ & $2(3.8 \%)$ & $0(0.0 \%)$ & & $0(0.0 \%)$ & $3(5.2 \%)$ & $0(0.0 \%)$ & \\
\hline Gujarati & 7 (7.0\%) & $6(17.6 \%)$ & 0 (0.0\%) & $1(7.7 \%)$ & & $3(11.5 \%)$ & $3(5.2 \%)$ & $1(6.3 \%)$ & \\
\hline Hindi & $16(16.0 \%)$ & $2(5.9 \%)$ & $11(20.8 \%)$ & $\begin{array}{r}3 \\
(23.1 \%)\end{array}$ & & $0(0.0 \%)$ & $13(22.4 \%)$ & $\begin{array}{r}3 \\
(18.8 \%)\end{array}$ & \\
\hline Punjabi & $13(13.0 \%)$ & $3(8.8 \%)$ & 7 (13.2\%) & $\begin{array}{r}3 \\
(23.1 \%)\end{array}$ & & $4(15.4 \%)$ & $8(13.8 \%)$ & $1(6.3 \%)$ & \\
\hline Urdu & $16(16.0 \%)$ & $6(17.6 \%)$ & 9 (17.0\%) & $1(7.7 \%)$ & & $6(23.1 \%)$ & $8(13.8 \%)$ & $\begin{array}{r}2 \\
(12.5 \%)\end{array}$ & \\
\hline Other & $15(15.0 \%)$ & $4(11.8 \%)$ & $11(20.8 \%)$ & $1(7.7 \%)$ & & $3(11.5 \%)$ & $11(19.0 \%)$ & $1(6.3 \%)$ & \\
\hline
\end{tabular}

All percentages are calculated by dividing the number within the cell by the $n$-value for that corresponding column. *An asterisk denotes a statistically significant $p$-Value for its corresponding category, which was set at $p \leq 0.05$.

they subsequently provided verbal consent of their willingness to participate anonymously in the study. Participants were also informed that if they agreed to take the survey, they could withdraw at any time and would not be penalized for doing so. A paper survey was given to all subjects, but research team members provided options for participants to complete it verbally or fill it out on their own; this was done based on the subject's preference. Criteria for inclusion are people who self-identify as South Asian.

\section{Measures}

The 10-question survey (Supplementary Material) was administered as described (either verbally or on paper) to ascertain each participant's familiarity of and knowledge about DOs and osteopathic medicine. Prior to distribution, the survey questions were reviewed by a department chair (S.Y.) at the NYIT College of Osteopathic Medicine who actively practices OMM and is board certified by the American Osteopathic Board of Family Physicians and American Osteopathic Board of Neuromusculoskeletal Medicine. The survey included questions on participant demographics (age, sex, number of years in the US, birthplace, level of education), language (primary language, English proficiency), healthcare utilization (type of doctor seen, yearly healthcare visits), knowledge of OMM, and a question asking who the participant would see if they presented with low back pain (a common condition where OMM has been shown as an effective treatment) [12].

The survey was offered in English and Hindi (Supplementary Material), for reasons described previously. While the term "South Asian" certainly encompasses much more than just the Indian population or those proficient in Hindi, the demographic data reported for our specific study area motivated the development of a Hindi survey to be provided alongside one in English, to allow us to maximize the potential respondent pool [11]. However, all study participants utilized the English version of the consent form and survey; no participants used the Hindi versions provided by the research team.
The survey was modeled from previous studies among other Chinese and Korean communities in the New York area (with 120 and 105 participants, respectively) $[6,7]$ that also assessed knowledge of OMM and osteopathic physicians. No power analysis was done prior to survey data collection, but the sample size for this study was based on those prior studies [6, 7].

\section{Data analysis}

Survey data obtained by a questionnaire was transcribed from the paper forms into REDCap, a secure web application designed for clinical and translational research. Each survey was entered with a separate participant ID, which helped maintain data sets specific to the individual who completed the survey, but did not contain any participant specific identifiers. Responses from the questionnaire were exported to Microsoft Excel (Microsoft, Inc.) and SPSS (SPSS, Inc.). p-values were calculated using the Kruskal-Wallis and Chi-Square tests. The KruskalWallis test was applied to compare the medians between groups that were measured in continuous scales (for variables "age" and "length of time in US in years") while the Chi-Square test was used to compare the proportions between groups that were measured in categorical scales (for all other variables). The level of significance for this study $(\boldsymbol{\alpha})$ was set at 0.05 for statistical significance.

\section{Results}

Of 100 participants, 53 (53\%) were male and 47 (47\%) were female; participant ages ranged from 18 to 81 years (mean, 41.2 years; median range, 18-29 years: 29 participants [29\%]; Table 1). The majority of the participants were born in India (52 of 100 [52\%]), Pakistan (21 of 100 [21\%]), and the United States (14 of 100 [14\%]). 
Thirty-four participants (34.0\%) had heard of OMM and $26(26.0 \%)$ had knowledge of what a DO physician does. Of the 34 who had knowledge of OMM, 24 (70.6\%) also indicated knowledge of what a DO physician does; likewise, 24 of the 26 participants who had knowledge of DOs (92.3\%) reported also having knowledge of OMM.

Survey participants were more likely to have knowledge of DOs if they were born or had lived longer in the United States. Of the 14 respondents born in the US, 8 indicated knowledge of what a DO physician does, while only 18 of the 86 respondents born in other countries indicated knowledge ( 57.1 vs. $20.9 \%$; $p=0.006$; Table 1 ). Of those 18 participants, nine were born in India (34.6\%), seven from Pakistan (26.9\%), and two from others (7.7\%). In comparison, the respondents born in other countries made up the majority of the participants who did not have knowledge of DOs (55 of 58, 94.8\%, Table 1). Those who had lived longer in the US (more than 26 years) were more likely to have knowledge of DOs as they made up 11 of the 26 respondents who have knowledge of DOs (42.3\%; $\mathrm{p}=0.039$; Table 1). The participants who indicated knowledge of DOs had a median 24 years of stay in the US vs. 15 years of stay for those who had no knowledge.

In contrast, participants who spoke a primary language other than English or who had lived in the United States for a shorter time were less likely to have knowledge

Table 2: Health habits of participants vs. those with knowledge of osteopathic physicians and osteopathic manipulative medicine (OMM).

\begin{tabular}{|c|c|c|c|c|c|c|c|c|c|}
\hline Answer & $\begin{array}{r}\text { All partici- } \\
\text { pants }(n=100)\end{array}$ & $\begin{array}{r}\text { Knowledge of } \\
\text { OMM }(n=34)\end{array}$ & $\begin{array}{r}\text { No knowl- } \\
\text { edge of OMM } \\
(n=53)\end{array}$ & $\begin{array}{l}\text { Unsure } \\
(n=13)\end{array}$ & $\begin{array}{c}\text { p- } \\
\text { Value }\end{array}$ & $\begin{array}{r}\text { Knowledge of } \\
\text { what osteopathic } \\
\text { physicians do } \\
(n=26)\end{array}$ & $\begin{array}{r}\text { No knowledge of } \\
\text { what osteopathic } \\
\text { physicians do } \\
(n=58)\end{array}$ & $\begin{array}{l}\text { Unsure } \\
(n=16)\end{array}$ & $\begin{array}{l}\text { p- } \\
\text { Value }\end{array}$ \\
\hline \multicolumn{10}{|c|}{ Do you see a doctor regularly? } \\
\hline Yes & 87 (87.0\%) & $31(91.2 \%)$ & $43(81.1 \%)$ & $\begin{array}{r}13 \\
(100 \%)\end{array}$ & 0.13 & $24(92.3 \%)$ & $48(82.8 \%)$ & $\begin{array}{r}15 \\
(93.8 \%)\end{array}$ & 0.33 \\
\hline No & $13(13.0 \%)$ & $3(8.8 \%)$ & $10(18.9 \%)$ & $0(0.0 \%)$ & & $2(7.7 \%)$ & $10(17.2 \%)$ & $1(6.3 \%)$ & \\
\hline \multicolumn{10}{|c|}{ In your hometown, what kind of doctor do you see? } \\
\hline Family doctor & $95(95.0 \%)$ & $33(97.1 \%)$ & $50(94.3 \%)$ & $\begin{array}{r}12 \\
(92.3 \%)\end{array}$ & 0.77 & $25(96.2 \%)$ & $55(94.8 \%)$ & $\begin{array}{r}15 \\
(93.8 \%)\end{array}$ & 0.94 \\
\hline $\begin{array}{l}\text { Osteopathic } \\
\text { physician (DO) }\end{array}$ & $2(2.0 \%)$ & $2(5.9 \%)$ & $0(0.0 \%)$ & $0(0.0 \%)$ & 0.14 & $2(7.7 \%)$ & $0(0.0 \%)$ & $0(0.0 \%)$ & 0.06 \\
\hline Chiropractor & $8(8.0 \%)$ & $1(2.9 \%)$ & $6(11.3 \%)$ & $1(7.7 \%)$ & 0.37 & $1(3.8 \%)$ & $6(10.3 \%)$ & $1(6.3 \%)$ & 0.57 \\
\hline Acupuncturist & $4(4.0 \%)$ & $1(2.9 \%)$ & 2 (3.8\%) & $1(7.7 \%)$ & 0.75 & $1(3.8 \%)$ & $2(3.4 \%)$ & $1(6.3 \%)$ & 0.88 \\
\hline $\begin{array}{l}\text { Oriental medi- } \\
\text { cine doctor }\end{array}$ & $1(1.0 \%)$ & $1(2.9 \%)$ & $0(0.0 \%)$ & $0(0.0 \%)$ & 0.38 & $1(3.8 \%)$ & $0(0.0 \%)$ & $0(0.0 \%)$ & 0.21 \\
\hline $\begin{array}{l}\text { Physical } \\
\text { therapist }\end{array}$ & $5(5.0 \%)$ & $2(5.9 \%)$ & $3(5.7 \%)$ & $0(0.0 \%)$ & 0.67 & $2(7.7 \%)$ & $3(5.2 \%)$ & $0(0.0 \%)$ & 0.54 \\
\hline $\begin{array}{l}\text { Physician } \\
\text { assistant }\end{array}$ & $8(8.0 \%)$ & $1(2.9 \%)$ & $5(9.4 \%)$ & $\begin{array}{r}2 \\
(15.4 \%)\end{array}$ & 0.32 & $1(3.8 \%)$ & $5(8.6 \%)$ & $\begin{array}{r}2 \\
(12.5 \%)\end{array}$ & 0.58 \\
\hline Other & $2(2.0 \%)$ & $0(0.0 \%)$ & $2(3.8 \%)$ & $0(0.0 \%)$ & 0.41 & $0(0.0 \%)$ & $2(3.4 \%)$ & $0(0.0 \%)$ & 0.48 \\
\hline \multicolumn{10}{|c|}{ If you had low back pain, what doctor would you go see? } \\
\hline Family doctor & $54(54.0 \%)$ & $14(41.2 \%)$ & $34(64.2 \%)$ & $\begin{array}{r}6 \\
(46.2 \%)\end{array}$ & 0.09 & $10(38.5 \%)$ & $34(63.8 \%)$ & $\begin{array}{r}7 \\
(43.8 \%)\end{array}$ & 0.07 \\
\hline $\begin{array}{l}\text { Osteopathic } \\
\text { physician (DO) }\end{array}$ & $7(7.0 \%)$ & $5(14.7 \%)$ & $1(1.9 \%)$ & $1(7.7 \%)$ & 0.07 & $5(19.2 \%)$ & $1(1.7 \%)$ & $1(6.3 \%)$ & 0.014 \\
\hline Chiropractor & $16(16.0 \%)$ & $6(17.6 \%)$ & $7(13.2 \%)$ & $\begin{array}{r}3 \\
(23.1 \%)\end{array}$ & 0.65 & $6(23.1 \%)$ & $6(10.3 \%)$ & $\begin{array}{r}4 \\
(25.0 \%)\end{array}$ & 0.19 \\
\hline Acupuncturist & $3(3.0 \%)$ & $1(2.9 \%)$ & $1(1.9 \%)$ & $1(7.7 \%)$ & 0.55 & $1(3.8 \%)$ & $1(1.7 \%)$ & $1(6.3 \%)$ & 0.62 \\
\hline $\begin{array}{l}\text { Oriental medi- } \\
\text { cine doctor }\end{array}$ & $1(1.0 \%)$ & $0(0.0 \%)$ & 1 (1.9\%) & $0(0.0 \%)$ & 0.64 & $0(0.0 \%)$ & 1 (1.7\%) & $0(0.0 \%)$ & 0.69 \\
\hline $\begin{array}{l}\text { Physical } \\
\text { therapist }\end{array}$ & $10(10.0 \%)$ & 5 (14.7\%) & 4 (7.5\%) & 1 (7.7\%) & 0.53 & 4 (15.4\%) & 5 (8.6\%) & 1 (6.3\%) & 0.55 \\
\hline $\begin{array}{l}\text { Physician } \\
\text { assistant }\end{array}$ & $4(4.0 \%)$ & $0(0.0 \%)$ & $3(5.7 \%)$ & 1 (7.7\%) & 0.32 & $0(0.0 \%)$ & $3(5.2 \%)$ & $1(6.3 \%)$ & 0.47 \\
\hline Other & 15 (15.0\%) & 6 (17.6\%) & $8(15.1 \%)$ & 1 (7.7\%) & 0.69 & $2(7.7 \%)$ & 11 (19.0\%) & $\begin{array}{r}2 \\
(12.5 \%)\end{array}$ & 0.39 \\
\hline
\end{tabular}

All percentages are calculated by dividing the number within the cell by the $n$-value for that corresponding column. 
of DOs. Of the 58 participants who indicated no knowledge of DOs, $46(79.3 \%)$ spoke a primary language other than English ( $\mathrm{p}=0.042$; Table 1). Those languages included Hindi (13, 22.4\%), Punjabi (8, 13.8\%), Urdu (8, 13.8\%), Bengali (3, 5.2\%), Gujarati (3, 5.2\%), and others (11, 19.0\%). Male participants were also less likely to have knowledge of OMM (men, 33 of 53 [62.3\%] vs. women, 20 of 53 [37.7\%]; $\mathrm{p}=0.036$; Table 1). Age, education level, and English proficiency were not found to have any statistically significant association with knowledge of OMM or DOs (Table 1).

There was no statistically significant difference found in knowledge of DOs or OMM between participants who visited their doctor regularly vs. those who did not (Table 2). Of 100 participants who reported regularly seeing their doctor, 95 (95\%) reported seeing their family physician (Table 2). Seven of 100 participants $(7 \%)$ indicated that they would see a DO physician for low back pain, while 54 (54\%) would see a family doctor, 16 (16\%) would see a chiropractor, and 10 $(10 \%)$ would see a physical therapist (Table 2).

\section{Discussion}

A limited awareness of DOs and OMM exists within the South Asian community in Hicksville, New York. Among the factors assessed in this survey study, knowledge of DOs was negatively associated with male sex, location of birth outside of the United States, having spent less time in the United States, and a non-English primary language.

Previous studies of other Asian populations in New York city showed that different factors influenced participant knowledge about DOs and OMM [6, 7]. In the Chinese community, factors like age, English proficiency, and education were associated with having knowledge of DOs [6]. In the Korean community, primary language was the main determinant for knowledge of DOs and OMM [7]. None of the participants in that study [7] spoke English as their primary language; most indicated that Korean was their primary language, and the majority $(86.4 \%)$ had no knowledge of OMM). Our results suggest that knowledge of OMM and DOs among this particular South Asian study population are influenced by a different set of factors compared with Chinese and Korean communities of prior studies [6,7], which exemplifies why the disaggregation of data on Asians is necessary and important.

In the US, chronic low back pain is the second most common cause of disability in adults and has a prevalence of $13.1 \%$ [13, 14]. A study conducted in Bangladesh, India, Nepal, Pakistan, and Sri Lanka found that the prevalence of back pain in older adults who engaged in some level of physical activity was $64.8,19.8,69.5,40.6$, and $36.2 \%$ respectively [15]. In our study, the majority of participants were of Indian or Pakistani descent (Table 1), so it may be appropriate to assume that low back pain is represented in our study population.

Most survey participants responded that they would manage their low back pain by seeking treatment from a family doctor (54\%), but only $7.0 \%$ of participants indicated that they would specifically see an osteopathic physician. This could be due to the fact that a majority of DO physicians do not use OMM; one survey showed that $77.7 \%$ of the 1,683 DO physicians who responded only used OMM on less than $5.0 \%$ of their patients; $45.6 \%$ of the surveyed population were family doctors [16]. It is possible that for this reason, participants in our study may not be able to distinguish between DO and MD family practitioners. Future studies might evaluate whether participants are able to make a distinction between an osteopathic (DO) physician or allopathic (MD) physician, and whether it has an impact on the care they seek. Interestingly, in a study of 63,966 participants in the United Kingdom, South Asian participants were more likely than White participants to visit a general practitioner to manage their musculoskeletal pain [17]. This may be a possible reason why participants in our study would choose to see a family practice doctor for their low back pain because they are accustomed to doing so.

Lack of awareness of OMM may also cause participants to seek other treatment modalities. For example, $16 \%$ of our participants indicated they would choose to see a chiropractor for low back pain. Many of the techniques in chiropractic therapy share similar mechanisms to OMM, which can make these participants more receptive to OMM [18]. Specifically for the South Asian population, management of chronic low back pain can also include Ayurvedic massage (Sahacharadi Taila), which is popular in India and shown to be effective for short term pain relief [19]. Ayurvedic tenets are similar to some tenets of osteopathic medicine, such as the concept of bodily interconnectedness or bodily unity, and the idea that imbalance or disruption of harmony causes muscular pathologies called Vata diseases [20]. A group of Ayurvedic practitioners (Vaidya) also practice traditional bone setting and treat muscular pains and blood clots, which are viewed as related pathologies [21]. One technique is called puttur $k a t t u$, which is the setting of fractures and dislocations [22]. Perhaps osteopathic physicians could promote more interest in osteopathic medicine within the South Asian population by drawing parallels to traditional Ayurvedic principles and practices.

There are no known osteopathic organizations recognized by the Osteopathic International Alliance in India [23]. The shortage of osteopathic training programs 
proposes a challenge to osteopathic awareness in South Asia. One possible reason for the shortage is the inability to distinguish osteopathy performed by osteopaths in India and osteopathic medicine performed by DOs in the US. Osteopaths in India solely practice osteopathic manipulation, whereas DOs can perform OMM in addition to their general practice of medicine [24]. Osteopathy in India may unintentionally predispose the general public to misconstrue the osteopathic medicine practiced by DOs, thereby not necessitating the demand for osteopathic training programs in India. A second reason for the shortage is the challenge for foreign trained medical professionals to practice in India. According to the Indian Medical Council Act of 1956, foreign medically trained Indian citizens are not allowed to practice in India unless they obtain an eligibility certificate that permits them to sit for the screening test, an entrance exam required for students who wish to pursue medical education [25]. The most recent Amendment of 2018 to the screening test regulations written in 2002 mandatorily qualifies foreign trained medical Indian citizens for the National Eligibility cum Entrance Test (NEET) and the result of the NEET is treated as an eligibility certificate [25]. The NEET allows foreign trained physicians to take a step closer to practice in India that was not initially present in the Act of 1956 . However, the process remains tedious and difficult, which still affects the ability to create osteopathic training programs in India.

\section{Limitations}

There were several limitations to this study. Hicksville is but one of many high-density areas of South Asian communities in New York, which may not be a true representation of osteopathic knowledge in the overall community. Furthermore, surveys were conducted on a single day at specific locations during the afternoon and evening, which may have failed to account for South Asian community members that are still working or not present in the area. Unfortunately, for the survey questions asking about the kind of doctor participants would see in their hometown and for low back pain, we did not provide definitions of the different types of healthcare providers. Thorough distinctions should also have been mentioned to prevent possible confusion between separate specialties included under the umbrella of family doctors. Also, there may have been more selection bias toward younger community members who were more willing to participate compared with older participants, which may have skewed the data toward a higher awareness of osteopathic medicine. Surveyors may have approached participants that appeared more fluent or approachable. A language barrier existed between our survey conductors and the nonnative English-speaking participants, which could have prevented proper interviews and answers. Due to the lack of proper translation of "osteopathic medicine" in other languages, subjects may have denied knowledge of osteopathic treatment despite prior exposure. Future studies should be done at varying times of the day using a qualitative or mixed methods design to account for the disparities of osteopathic awareness among different ethnicities within the South Asian community. For those communities that have a sufficient South Asian population located near an osteopathic institution, a follow up study could be conducted to explore the correlation of proximity and osteopathic knowledge.

\section{Conclusions}

There was a general lack of knowledge of osteopathic physicians and OMM among participants in the South Asian community in Hicksville, New York. Sex, birthplace, length of time in the US, and primary language used were all factors that influenced knowledge of osteopathic medicine. Those who use English as their primary language and those who were born or who had lived longer in the US were found to be more likely to have knowledge of DOs, as were female participants. The differences between our results and those found in previous studies of the Chinese and Korean communities highlight the importance of disaggregation of Asian populations. This study adds to the research on osteopathic awareness in ethnic communities and may further promote more targeted efforts to develop educational resources and programs to increase public knowledge of OMM and osteopathic physicians.

Acknowledgments: The authors would like to acknowledge Sonu Sahni, MD and Justin Chin, DO for providing the inspiration that led to the development of this paper. We also recognize the invaluable work of Min-Kyung Jung, $\mathrm{PhD}$ in the Office of Research at New York Institute of Technology College of Osteopathic Medicine, for her assistance in statistical data analysis.

Research funding: None reported.

Author contributions: All authors provided substantial contributions to conception and design, acquisition of data, or analysis and interpretation of data; all authors drafted the article or revised it critically for important intellectual content; all authors gave final approval of the version of the article to be published; and all authors agree 
to be accountable for all aspects of the work in ensuring that questions related to the accuracy or integrity of any part of the work are appropriately investigated and resolved.

Competing interests: None reported.

Informed consent: Participants were initially given a paper consent form (approved by the NYIT Institutional Review Board) to read over and they subsequently provided verbal consent of their willingness to participate anonymously in the study.

Ethical approval: The study obtained exemption approval by the New York Institute of Technology Institutional Review Board for the Protection of Human Participants (Protocol BHS-1514).

\section{References}

1. Aacom.org. 2021. History of osteopathic medicine-its origins and approach to healthcare. Available from: https://www.aacom.org/ become-a-doctor/about-osteopathic-medicine/history-ofosteopathic-medicine [Accessed 14 June 2021].

2. What is osteopathic medicine? American Osteopathic Association. Available from: https://osteopathic.org/what-is-osteopathicmedicine/ [Accessed 25 Apr 2021].

3. Osteopathic Manipulative Medicine (OMM) Explained. Bethesda: American Association of Colleges of Osteopathic Medicine. Available from: https://www.aacom.org/docs/default-source/ become-a-do/aacom-omm-one-pager_v7-(1).pdf?fbclid=IwAR 1P9CN48WmfhNyl3wFABqGKAW-WfyyPm2XsG10fne3KJ3D MvHwxjXdBfOo [Accessed 19 Mar 2021].

4. The difference between U.S.-trained osteopathic physicians and osteopaths trained abroad. How are U.S. Osteopathic doctors different than those trained abroad. Available from: https://www.aacom.org/ become-a-doctor/about-om/US-vs-abroad [Accessed 31 Jan 2021].

5. Gougian RL, Berkowitz MR. Gray zone: why a delayed acceptance of osteopathic medicine persists in the international community. J Am Osteopath Assoc 2014;114:754-60.

6. Chin J, Li S, Yim G, Zhou Y, Wan P, Dube E, et al. Perceptions of the osteopathic profession in New York City's Chinese Communities. Fam Med Commun Health 2020;8:e000248.

7. Chin J, Woo H, Choi D, Dube E, Volokitin M, Lomiguen C. Perceptions of the osteopathic profession in New York City's Korean communities. Osteopath Fam Phys 2021:12-8. https://doi. org/10.33181/13011.

8. Licciardone JC. Awareness and use of osteopathic physicians in the United States: results of the second osteopathic survey of health care in America (OSTEOSURV-II). J Am Osteopath Assoc 2003;103: 281-9.

9. Licciardone JC. Validity and reliability of the osteopathic survey of health care in America (OSTEOSURV). J Am Osteopath Assoc 2003; 103:89-101.
10. Licciardone JC, Kearns CM, Ruggiere P. Background and methodology of the osteopathic survey of health care in America 2010 (OSTEOSURV 2010). J Am Osteopath Assoc 2011;111: 670-84.

11. Census.gov. Available from: https://data.census.gov/cedsci/ table $\mathrm{g}=1600000$ US3634374\&tid=ACSDP5Y2019.DP05 [Accessed 25 Mar 2021].

12. Franke H, Franke JD, Fryer G. Osteopathic manipulative treatment for nonspecific low back pain: a systematic review and metaanalysis. BMC Muscoskel Disord 2014;15:286.

13. Freburger J, Holmes G, Agans R, Jackman A, Darter J, Wallace A, et al. The rising prevalence of chronic low back pain. Arch Intern Med 2009;169:251.

14. Shmagel A, Foley R, Ibrahim H. Epidemiology of chronic low back pain in US adults: data from the 2009-2010 National Health and Nutrition Examination Survey. Arthritis Care Res 2016;68:1688-94.

15. Ghose B, Tang S, Yaya S, Feng Z. Participation in physical activity and back pain among an elderly population in South Asia. J Pain Res 2017;10:905-13.

16. Healy CJ, Brockway MD, Wilde BB. Osteopathic manipulative treatment (OMT) use among osteopathic physicians in the United States. J Am Osteopath Assoc 2021;121:57-61.

17. Njobvu P, Hunt I, Pope D, Macfarlane G. Pain amongst ethnic minority groups of South Asian origin in the United Kingdom: a review. Rheumatology 1999;38:1184-7.

18. Friedman H. Osteopathy vs. chiropractic. J Fam Pract 1993;37:221-2.

19. Kumar S, Rampp T, Kessler C, Jeitler M, Dobos Gustav, Lüdtke R, et al. Effectiveness of Ayurvedic massage (Sahacharadi Taila) in patients with chronic low back pain: a randomized controlled trial. J Altern Complement Med 2017;23:109-15.

20. Guha A. What is the philosophy of Ayurvedic medicine?. Taking charge of your health and wellbeing. Available from: https:// www.takingcharge.csh.umn.edu/what-philosophy-ayurvedicmedicine [Accessed 24 Jan 2021].

21. Sujatha V. Pluralism in Indian medicine: medical lore as a genre of medical knowledge. Contrib Indian Sociol 2007;41:169-202.

22. Panda AK, Rout S. Puttur kattu (bandage)-a traditional bone setting practice in south India. J Ayurveda Integr Med 2011;2: 174-8.

23. Full Member Organisations. Osteopathic International Alliance. Available from: https://oialliance.org/member-organisations [Accessed 31 Jan 2021].

24. Osteopathy Course Distance Learning Program. Osteopathy courses in India for physiotherapists. Available from: https:// capri4physio.com/courses/osteopathy-courses/3 [Accessed 31 Jan 2021].

25. राष्ट्रीय आयुर्वज्जितन आयोग NATIONAL MEDICAL COMMISSION. NMC. Available from: https://www.nmc.org.in/rules-regulations/ screening-test-regulations-2002 [Accessed 31 Jan 2021].

Supplementary Material: The online version of this article offers supplementary material (https://doi.org/10.1515/jom-2021-0060). 